\title{
Methodological recommendations for conducting control work in mathematics teaching
}

Article Info:

Article history: Received 2021-08-20 / Accepted 2021-12-16 / Available online 2021-12-21

doi: $10.18540 /$ jcecvl7iss4pp13611-01-09e

\begin{abstract}
Shivkant Tiwari
ORCID: https://orcid.org/0000-0003-0942-3467

Department of Mathematics, Lukhdhirji Engineering College, Morbi 363642, Gujarat, India

E-mail: shivkant.math@gmail.com

Dragan Obradovic

ORCID: https://orcid.org/0000-0001-5871-6958

Elementary school "Jovan Cvijic", Kostolac-Pozarevac, Serbia

E-mail: dragishaobradovic@yahoo.com

Laxmi Rathour

ORCID: https://orcid.org/0000-0002-2659-7568

Ward number - 16, Bhagatbandh, Anuppur 484 224, Madhya Pradesh, India

E-mail: laxmirathour817@gmail.com

Lakshmi Narayan Mishra

ORCID: http://orcid.org/0000-0001-7774-7290

Department of Mathematics, School of Advanced Sciences,

VIT University, Vellore 632 014, Tamil Nadu, India

E-mail: lakshminarayanmishra04@gmail.com

Vishnu Narayan Mishra

ORCID: http://orcid.org/0000-0002-2159-7710

Department of Mathematics, Indira Gandhi National Tribal University, Lalpur, Amarkantak, Anuppur, Madhya Pradesh 484 887, India

E-mail: vishnunarayanmishra@gmail.com
\end{abstract}

\begin{abstract}
The importance of mathematics as a subject in building intellectually strong personalities, creating and nurturing work habits in students, training them for independent work, are undoubtedly important for acquiring permanent and active mathematical knowledge as a basis for studying mathematics at the next level of education. There is an undoubted need to improve the teaching practice, the current teaching, which only transfers knowledge to the degree of recognition and reproduction.
\end{abstract}

Keywords: Mathematics teaching methodology, Control work in mathematics teaching, Mathematical analysis program.

\section{Introduction}

Mathematics as a subject in school has a prominent place in the entire educational program, not only as a subject that educates people, providing students with useful knowledge for life or continuing education, but also as a subject that has an educational function and broadly participates in building a scientific view. to the world. One of the requirements of teaching mathematics, as it is known, has the task to develop in students a sense of independent work, the ability to express clearly, logically and precisely, the habit of responsibility and orderliness in performing school and other tasks. Since students prepare for life at school, it largely depends on the school how it will enable students to 
cope with problem situations, both at work and in everyday life situations. If the question of training students for independent work in mathematics teaching is asked, traditional teaching, organized by old forms and methods of work, cannot give a complete answer to this question in terms of meeting the requirements of the program for primary and secondary school. There is an undoubted need that only by improving teaching practice, current teaching, which only transfers knowledge to the level of recognition and reproduction, must be replaced by teaching that will enable students to acquire knowledge independently, from planning to self-evaluation and creative application in everyday life situations.

The teaching process is still performed improvised, routinely, with a lot of practicality. The position of teachers and students is subordinate and superior. The teacher is an exclusive and inviolable organizer, where his word is first and last, with a lot of rigidity and distance, without self-criticism and critical work. The lecturer is more of an academic type, without democracy in work and teaching, uninterested in creative research. It sticks to the template according to the work program, does not improve and does not follow the literature to a sufficient extent, does not introduce innovations in the work. As for the student himself, he is just an object that needs to be "poured" knowledge into his head. He is more a passive observer than an active participant in the teaching process, who mechanically acquires knowledge to the level of reproduction, without greater interest in independent creative work, without democracy to participate in the organization of the teaching process together with the teacher, without the right to express their views.

By modernizing teaching, introducing innovative work, introducing modern forms and methods of work, introducing democracy and cooperation, with constant joint consultations in finding ways to solve certain educational situations in the teaching process, raises critical awareness among teachers and students in assessing and self-assessing work results. In the teaching of mathematics, problem situations should be used, ie forms of learning through problem solving should be used. Whether it is about processing, repeating, practicing, or applying mathematical knowledge in practice, one should constantly strive to discover facts, define definitions, and formulate rules, infer, reason, and seek new ideas in solving a mathematical problem. In order for students to be able to solve problem tasks, it is necessary to work gradually, systematically and thoughtfully, and to solve tasks according to the principle - from a simpler to a complex problem task. Without the ability of students to learn in the form of problem solving, there is no independence or creative learning.

\section{Methods of teaching mathematics}

The learning process is at the core of every human activity. Learning is not just reading textbooks and attending lectures and seminars. Most life situations are more or less a kind of learning. Every time something new is done, knowledge is acquired is the result of lived experience. Learning is reading newspapers and books, crossing the street, riding a bus, watching a movie or TV series, all these everyday activities represent different learning styles. During the teaching process, in addition to transmitting new teaching content, it is necessary to work on motivating students. Motivation should be both external and internal: students should see ways they can apply what they have learned to appreciate their work. You also need to understand that learning is for your own benefit. The role of the teacher is to show the students with different methods of learning in different areas of science how to treat newspapers on a daily basis and how to use them throughout your life. It is important to be comprehensive in creating educational programs. Savic et al. (2012) discussed the realization of mathematics teaching that can be defined by a set of different methods and their basic functions. Proper order of application of methods can give positive results, deviation from the order or nonuse of the same can cause negative effects in terms of acceptance of information by students. The teaching of mathematics should be contained in the following methods: 
- Oral presentation method - the teacher explains, the student listens and partially acquires knowledge. This is a very important method, but insufficient for a clear presentation of the new material, the math class must not be reduced only to this method.

- Method of discussion - interaction that takes place in the form of setting and solving a particular problem, initiates students' thinking activities. The method should be implemented in the presence of full attention. Mathematics classes are characterized by the current application of a large number of mathematical concepts. Consequences are usually cases when the teacher explains more complex concepts without the students adopting the basic concepts due to incomplete comprehensibility.

- Demonstration method - based on presenting or clarifying concepts through prepared examples or tasks. Tasks should be characteristic in terms of the type of problem or method of solution.

- Method of independent exercises - the student independently solves the set task. Tasks can be solved on the board in the notebook, but also with the help of software specialized in mathematics. This kind of work can be realized outside the school, where it is recommended that the contents be more complex in relation to the planned teaching material.

- Method of working with literature - this method is almost not applicable in teaching, if used, it is usually contained in the independent work of students on a particular topic whose presentation is through a seminar paper. The use of this method in teaching should help students in mastering different ways of using literature, accepting different views on a certain concept, i.e. creating critical thinking.

In general, students are individuals who respond to different ways of learning. This means that methods that suit most of the various ways of learning must be used in the learning process. By Mladenovic (1986), tendencies towards mathematics are different. Also, students' prior knowledge and needs are different. Therefore, in the teaching of mathematics, there must be informational feedback in relation to the work of the teacher and each student activity. The existence of such a connection is no longer conditioned by the computer literacy of students but, for the most part, of mathematics teachers. The main goal of teacher training is to achieve information and technical possibilities for partial or complete application of adaptive learning through the use of various educational software.

\section{Mathematical analysis programs}

Lecturers tend to rely on their own memories of what they learned when they were in school. However, for many reasons, the situation today is much different. The curriculum should be observed at this time . Baumslag (2000) points out a few important facts. Students coming from school are not sufficiently prepared. In high school, evidence is given only as an irrelevant form and dacians are not expected to understand, let alone know. When they come to the university, where they learn that definitions and evidence are very important parts of the course, they realize that they are at a loss. Changes in schools, changes in the curriculum, reduced criteria and a larger volume of enrollment have led to the admission of weaker and less prepared students. They are less willing to fight to find a solution. They prefer to give up after a short attempt to solve the problem. At the same time, instead of more students, less time is devoted, which especially affects weak students. Funding for studies has not increased in proportion to the number and needs. All these reasons have contributed to the facilitation and simplification of teaching and the subject itself. 
An essential feature of a modern university is excellence. At university, the goal has always been for students to acquire knowledge and the highest possible standard of academic success. They are expected to enter society and produce new ideas and new technologies. If the standards of courses drop dramatically and adapt to weak and poorly educated students, the university will fail in its most important obligation to produce outstanding degrees, capable, imaginative, with a wide range of knowledge and skills. It is difficult to adapt the course to good students and they may find it boring. Therefore, there is an opinion that smart students should be taken care of. That will surely work. The smart ones do well and cope successfully with difficulties. What is the solution? We must not neglect better students and demanding courses should be provided for them. Courses appropriate to different student abilities and interests must be provided at the university. In addition, you should keep in mind the courses that are still waiting for students. Baumslag (2000), has each phase of the study should be designed according to the students who have passed to the next phase, and the material should continue where it was previously completed. According to Despotovic (2010), the curriculum contains several elements, among which are:

1. area and order of learning - matrix of goals for individual levels of education, which are grouped by areas;

2. Curriculum - a course plan that usually contains an explanation, topics, resources, and evaluation;

3. content overview - list of processed topics;

4. standards - a list of knowledge and skills that students possess after graduation;

5. textbooks - teaching material used in teaching.

Marsh points out that the curriculum consists of subjects that are most useful for modern life, and according to Smith, these are the outcomes that students should achieve. The term curriculum is mainly related to university teaching, ie university subjects with the meaning of the curriculum, ie. course program, curriculum, review content, review and schedule of lectures. Other authors consider that the curriculum is a part of the curriculum that is aimed at the specification of teaching units, which depends on the specification of the way of learning these units, which the methodology deals with.

Outcomes define what the student needs to know, understand, evaluate, and what he or she is able to do ... The curriculum does not deal so much with the question of what will be learned, how and when, but with the question of what will be learned. learned. According to Despotovic (2010), the curriculum is essentially a program of activities for teachers and students aimed at achieving certain goals and outcomes of education.

Attention is focused on what the student does in situations of interaction and organized learning, such as observation, problem solving, exchange of ideas and experiences, understanding, reasoning, critical thinking, constructing, experimenting, creating alternatives, etc.

There are three dominant approaches to creating a curriculum and its structure by Despotovic (2010):

(i) Content based / program-based approach. It is a traditional approach that lists the areas or topics to be taught. This approach is justified by the fact that it is not possible to predict what kind of knowledge will be needed in the near or distant future. The purpose of education in this spirit is to provide general, universal and structured knowledge that is presented through broader principles, concepts and theories. 
(ii) Activity-based and experience-based approach. In this approach, the primary influence is the choice and organization of methods, techniques, learning and teaching strategies. It enables the development of general abilities, critical thinking, formulation and problem solving.

(iii) Outcome based approach. The most important thing is what will be learned. Education and learning prepare the student to understand the context, to function in it. The end effect of learning is predetermined and clearly defined and becomes the primary thing in the learning process.

\section{Theoretical basis for making test tasks, for the discipline "mathematical analysis"}

The didactic unit is a logically independent part of the teaching material presented in the form of a study program approved in a certain way within a certain discipline, in its scope and structure that corresponds to the content components such as concept, theory, law, phenomenon. fact, subject, etc.

The peculiarity of the educational element is the simplicity, completeness and homogeneity of the information it describes. Before starting to choose the theoretical and practical material for teaching, it is necessary to correctly determine the educational elements, and then structure them. This will help to fully present the depth of study of the topic and the picture of the planned result.

Using this definition, we single out the educational elements for the elements of the discipline "Mathematical Analysis".

\subsection{Methodical recommendations for the implementation of control work}

1. Calculate the following limits:

$\lim _{x \rightarrow 0} \frac{\sqrt{x}+4 \sqrt[3]{x}}{\sqrt[3]{x^{2}}-\sqrt[3]{x}}$

Solution:

In this case we have the uncertainty of form $\frac{0}{0}$. To expand it, we are introducing a replacement $t^{6}=x$. You will notice that $t \rightarrow 0$, at $x \rightarrow 0$. We get:

$\lim _{x \rightarrow 0} \frac{\sqrt{x}+4 \sqrt[3]{x}}{\sqrt[3]{x^{2}}-\sqrt[3]{x}}=\lim _{x \rightarrow 0} \frac{t^{3}-4 t^{2}}{t^{4}-t^{2}}=\lim _{x \rightarrow 0} \frac{t-4}{t^{2}-1}=\frac{-4}{-1}=4$

$\lim _{x \rightarrow \frac{\pi}{2}} \frac{\cos x}{x-\frac{\pi}{2}}$

Solution:

We have an uncertainty of the form $\frac{0}{0}$. To reveal it, let us bring this fraction to a form that would allow the application of the first remarkable limit $\lim _{x \rightarrow 0} \frac{\sin x}{x}=1$. Let's introduce a substitution $t=\frac{\pi}{2}-x$. Note that $t \rightarrow 0$ for $x \rightarrow \frac{\pi}{2}$. We get: 


$$
\begin{aligned}
& \lim _{x \rightarrow \frac{\pi}{2}} \frac{\cos x}{x-\frac{\pi}{2}}=\lim _{t \rightarrow 0} \frac{\cos \left(\frac{\pi}{2}-t\right)}{-t}=-\lim _{t \rightarrow 0} \frac{\sin t}{t}=-1 \\
& \lim _{x \rightarrow \infty}\left(\frac{x-2}{x+2}\right)^{x}
\end{aligned}
$$

Solution:

We have an uncertainty of the form $1^{\infty}$. To reveal it, we bring this fraction to a form that would allow the application of the second remarkable limit $\lim _{x \rightarrow \infty}\left(1+\frac{1}{x}\right)^{x}=e$.

$\lim _{x \rightarrow \infty}\left(\frac{x-2}{x+2}\right)^{x}=\lim _{x \rightarrow \infty}\left(\frac{x+2-4}{x+2}\right)^{x}=\lim _{x \rightarrow \infty}\left(1+\frac{-4}{x+2}\right)^{x}$ Further, using the equalities $\lim _{x \rightarrow \infty}\left(1+\frac{1}{x+a}\right)^{x}=e$ and $\lim _{x \rightarrow \infty}\left(1+\frac{k}{x}\right)^{x}=e^{k}$, we get: $\lim _{x \rightarrow \infty}\left(1+\frac{-4}{x+2}\right)^{x}=e^{-4}$.

2. Establish at what points and what kind of discontinuities the function has:

$$
f(x)=\left\{\begin{array}{l}
2 x \text { npu }-4 \leq x \leq 0 \\
x^{2}+1 \text { при } 0<x \leq 5
\end{array}\right.
$$

Solution:

The domain of the function: as you can see from the system, in the first case the function is defined on the interval $[-4 ; 0]$, and in the second $(0 ; 5]$, therefore, the entire domain has the form: $D(f)=[-4 ; 5]$. If $x \in[-4 ; 0)$ then $f(x)=2 x$ - a continuous function, since it is a polynomial of the first degree (at a point the $x=-4$ function $f(x)$ is continuous on the right, since it is not defined to the left of this point). If $x \in(0 ; 5]$, then $f(x)=x^{2}+1$ is a continuous function as a polynomial of the second degree (at the point $x=5$ function $f(x)$ is continuous on the left, since it is not defined to the right of this point). To investigate the function for continuity at the point $x=0$ it is necessary to find at this point the one-sided limits of the function. We have $f(-0)=\lim _{x \rightarrow-0} f(x)=\lim _{x \rightarrow-0} 2 x=0, \quad f(+0)=\quad=\lim _{x \rightarrow+0} f(x)=\lim _{x \rightarrow+0}\left(x^{2}+1\right)=1$. Since one-sided limits exist, they are finite, but not equal - point $x=0$ a discontinuity point of the first kind, the magnitude of the jump is $f(+0)-f(-0)=1$.

Thus, the function $f(x)$ is continuous on the set $(-4 ; 0) \cup(0 ; 5)$, at the point $x=-4$ is continuous on the right, at the point $x=5$ - to the left, at the point $x=0$ suffers a break of the first kind, the magnitude of the jump is 1 .

3. Find derivatives of functions:

a)

$$
y=\frac{e^{x}-e^{-x}}{2}
$$

Solution: 


$$
\begin{aligned}
& y^{\prime}=\left(\frac{e^{x}-e^{-x}}{2}\right)^{\prime}=\frac{1}{2}\left(\left(e^{x}\right)^{\prime}-\left(e^{-x}\right)^{\prime}\right)=\frac{1}{2}\left(e^{x}+e^{-x}\right)=\frac{e^{x}+e^{-x}}{2} \\
& \text { b) } y=\ln \sqrt{\cos x}
\end{aligned}
$$

Solution:

We use the rule for differentiating a complex function:

$$
\begin{aligned}
& (f(g(x)))^{\prime}=f^{\prime}(g) \cdot g^{\prime}(x) \\
& \qquad y^{\prime}=(\ln \sqrt{\cos x})^{\prime}=\frac{1}{\sqrt{\cos x}} \cdot(\sqrt{\cos x})^{\prime}=\frac{1}{\sqrt{\cos x}} \cdot \frac{1}{2 \sqrt{\cos x}} \cdot \cos ^{\prime} x=\frac{-\sin x}{2 \cos x}=-\frac{1}{2} \operatorname{tg} x \\
& \text { Note that this result could be obtained by representing the function in the form } \frac{1}{2} \ln \cos x
\end{aligned}
$$

c) $y=e^{-x} \ln x$

\section{Solution:}

Let's use the rule of differentiation of the product of two functions: $(u v)^{\prime}=u^{\prime} v+u v^{\prime}$.

We get

$$
y^{\prime}=\left(e^{-x} \ln x\right)^{\prime}=-e^{-x} \cdot \ln x+\frac{e^{-x}}{x} \text {. }
$$

d)

$$
y=\operatorname{arctg} \frac{1}{x^{2}}
$$

Solution:

We again use the formula for the derivative of a complex function:

$$
\begin{aligned}
& (f(g(x)))^{\prime}=f^{\prime}(g) \cdot g^{\prime}(x) \text {. We get } \\
& y^{\prime}=\left(\operatorname{arctg} \frac{1}{x^{2}}\right)^{\prime}=\frac{1}{1+\frac{1}{x^{4}}} \cdot\left(\frac{1}{x^{2}}\right)^{\prime}=\frac{x^{4}}{x^{4}+1} \cdot\left(-\frac{2}{x^{3}}\right)=-\frac{2 x}{x^{4}+1}
\end{aligned}
$$

4. Write the equations of tangent and normal to the graph of the function

$$
y=\sin 2 x \text { at the point } x_{0}=\frac{\pi}{3} .
$$

Solution:

Let's write the equation of the tangent line: $y-f\left(x_{0}\right)=f^{\prime}\left(x_{0}\right)\left(x-x_{0}\right)$. In our case

$$
\begin{aligned}
& f\left(x_{0}\right)=\sin \frac{2 \pi}{3}=\frac{\sqrt{3}}{2}, f^{\prime}\left(x_{0}\right)=2 \cos \frac{2 \pi}{3}=-1 \text {. Substitute into the equation: } y-\frac{\sqrt{3}}{2}=-\left(x-\frac{\pi}{3}\right), \\
& \text { where } y=-x+\frac{\pi}{3}+\frac{\sqrt{3}}{2} \text { - the equation of the tangent line. }
\end{aligned}
$$


Let's write the normal equation:

$$
y-f\left(x_{0}\right)=-\frac{1}{f^{\prime}\left(x_{0}\right)} \cdot\left(x-x_{0}\right)
$$

this equation: $y-\frac{\sqrt{3}}{2}=x-\frac{\pi}{3}$, where $y=x-\frac{\pi}{3}+\frac{\sqrt{3}}{2}$ - is the normal equation.

5. Differentiate the function y (x), implicitly given by the equation

$$
2 x y^{2}-x^{2} y+x^{2}+2=0
$$

Solution:

We differentiate both sides of this equation with respect to the variable $\mathrm{x}$, taking into account what $\mathrm{y}$ is a function of the argument $\mathrm{x}$. We get: $\left(2 x y^{2}-x^{2} y+x^{2}+2\right)_{x}^{\prime}=2 y^{2}+4 x y y^{\prime}-2 x y-x^{2} y^{\prime}+2 x=0$. From the obtained equality, we express the derivative $y_{x}^{\prime}$ : $4 x y y^{\prime}-x^{2} y^{\prime}=2 x y-2 y^{2}-2 x$, where $y^{\prime}=\frac{2 x y-2 y^{2}-2 x}{4 x y-x^{2}}$

6. Differentiate the function given parametrically by equations

$$
\left\{\begin{array}{l}
x=2 \cos t^{2} \\
y=\sin t-3 t
\end{array}\right.
$$

Solution:

We use the rule of differentiation of a function defined parametrically:

$$
y_{x}^{\prime}=\frac{y_{t}^{\prime}}{x_{t}^{\prime}}
$$

We get:

$$
y_{x}^{\prime}=\frac{(\sin t-3 t)^{\prime}}{\left(2 \cos t^{2}\right)^{\prime}}=\frac{\cos t-3}{-4 t \sin t^{2}}=\frac{3-\cos t}{4 t \sin t^{2}} \text {. }
$$

7. Find the derivative of the function $y=(\sin x)^{\sin x}$ using logarithmic differentiation

Solution:

Let's write down the general formula for the logarithmic derivative: $y^{\prime}=f(x) \cdot(\ln f(x))^{\prime}$.

In our case: $y=(\sin x)^{\sin x} \Rightarrow \ln y=\ln (\sin x)^{\sin x} \Rightarrow \frac{y^{\prime}}{y}=\left(\ln (\sin x)^{\sin x}\right)^{\prime} \Rightarrow y^{\prime}=y$. $(\sin x \ln (\sin x))^{\prime}$

$$
\begin{aligned}
& =y\left(\cos x \ln (\sin x)+\sin x \cdot \frac{\cos x}{\sin x}\right)=(\sin x)^{\sin x} \cdot(\cos x \ln (\sin x)+\cos x) \\
& =(\sin x)^{\sin x} \cos x(\ln (\sin x)+1)
\end{aligned}
$$

\section{Conclusions}

Modern teaching of mathematics cannot be imagined without the application of modern educational technology. In modern organized mathematics teaching, the process of acquiring mathematical 
knowledge using modern educational technology, in addition to perceptions and ideas acquired through observation, includes very intense intellectual activities, abstract thinking, which should be especially taken into account. This means that the use of modern educational technology is in the function of the development of mathematical thinking and the successful adoption of mathematical concepts only if it ensures and encourages appropriate thinking activities of students. The application of modern educational technology in the realization of mathematical contents should create such a climate in the classroom that students gladly accept their obligations and effectively adopt the planned contents.

\section{References}

Baumslag B. (2000). "Fundamental of teaching mathematics at University level" Imperial College Press, London, Page-6.

Baumslag B. (2000). "Fundamental of teaching mathematics at university level" Imperial College Press, London, Page-14-22.

Despotovic M. (2010). "Curriculum development in vocational education" Faculty of Philosophy, University of Belgrade, Page-21.

Despotovic M. (2010). "Curriculum development in vocational education" Faculty of Philosophy, University of Belgrade, Page- 21.

Despotovic M. (2010). "Curriculum development in vocational education" Faculty of Philosophy, University of Belgrade, Page-29.

Mladenovic M. (1986). "Introduction of Innovation in mathematics teaching" II Yugoslav Symposium on Innovations Arandjelovac, publisher: magazine "Samoupravno vaspitanje", topic: INNOVATIONS in theory and practice, Loznica, Page-137, 20-23 March.

Savic A., Strbac Savic S., Gavrilovic J. \& Kostic Kovacevic I. (2012). "Methods of teaching mathematics" SED Conference Uzice., September. 